\title{
Weg des Lebens
}

\section{Künzler}

Vor kurzem habe ich eine kleine Serie von sieben Bildern $(12 \times 17 \mathrm{~cm})$ gemalt, der ich den Titel «Weg des Lebens" gegeben habe. Damit hat es folgende Bewandtnis: Am 8. Juli 2000 war die Hochzeit eines meiner Göttikinder festgesetzt. Man sollte nun als Geschenk u.a. eine Büchse mitnehmen, Inhalt frei, aber schön geschmückt.

Hinterher erfuhr man, dass an Bohnen, Konfitüre oder ähnliches gedacht wurde. Ich dachte damals nicht an das. Ich habe eine schön bemalte leere Guetslibüchse von mässiger Grösse gekauft. Nun aber wie füllen? Es kam mir die Idee, kleine Bilder zu malen. Der Gedanke, einen Weg des Lebens zu gestalten, kam mir erst mit der Zeit. Dann aber packte es mich und ich beschloss, sieben Stationen im Leben eines Menschen - der meisten Menschen - farblich zu komponieren. So entstanden "Geburt», "Adoleszenz", "Eintritt ins Berufsleben", "Produktives Leben", "Pensionierung", "Alter" und "Tod».

Es war sehr faszinierend, dies zu tun. Die Bilder sind aus Inspirationen, inneren Gefühlen und ein wenig Verstand heraus gewachsen. Sie sollen einerseits einfach Bilder sein, die als solche bestehen können, und andererseits doch auch eben diese Gefühle bestmöglich ausdrücken. Erklären kann man das einzelne in wenigen Worten kaum. Es ist eigentlich auch nicht nötig. Der Betrachter soll versuchen, die Wurzeln, aus denen er gewachsen ist, zu erspüren.

\section{Korrespondenz:}

Dr. med. David Künzler

Jakob-Zürrer-Strasse 35

CH-8915 Hausen am Albis

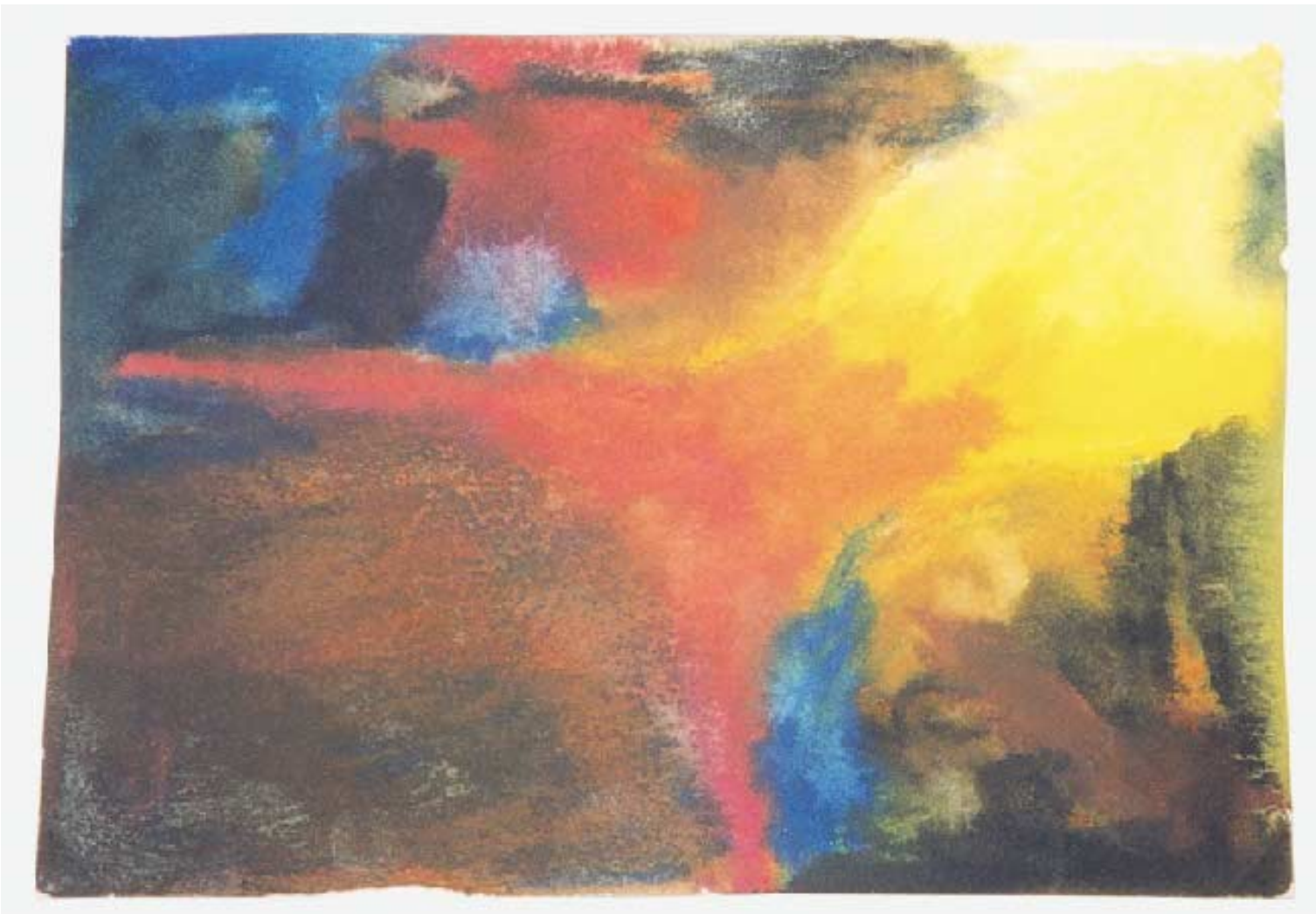

Geburt 


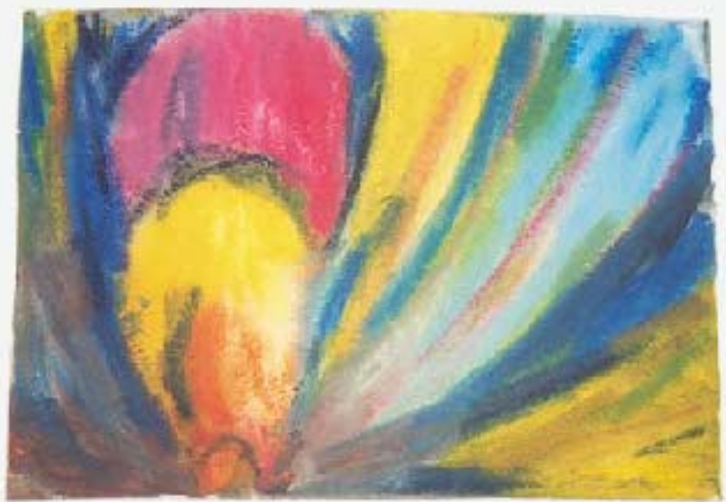

Adoleszenz

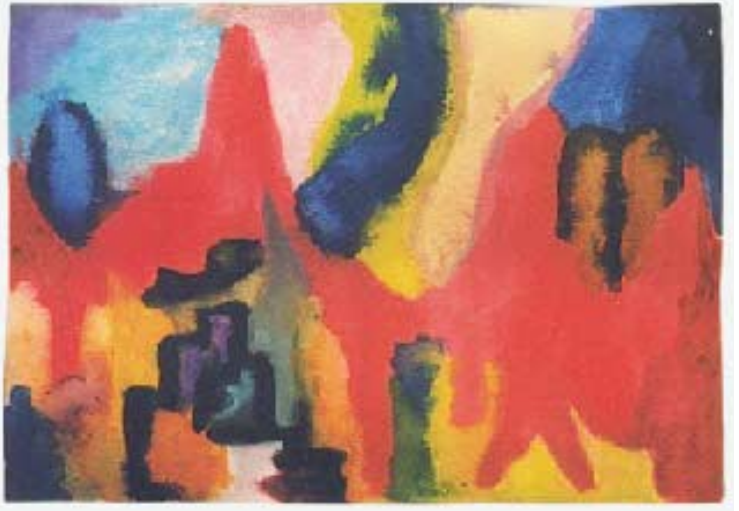

Produktives Leben

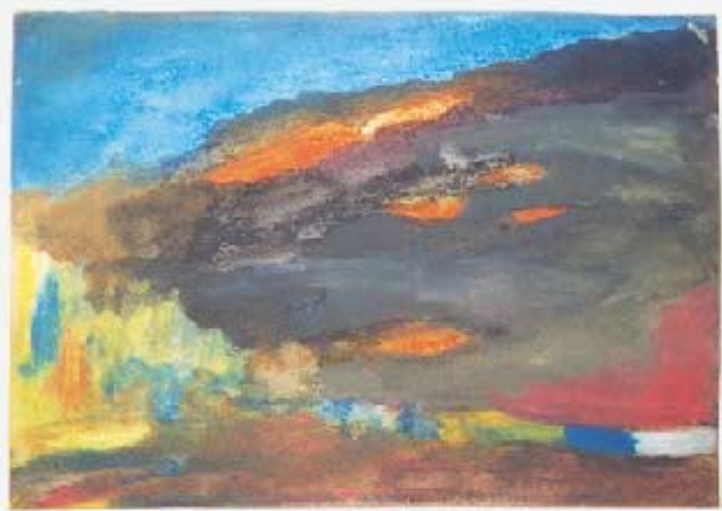

Alter

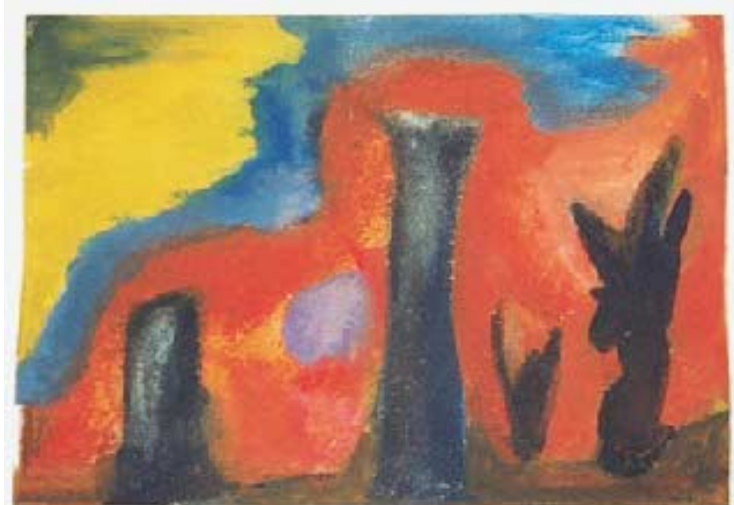

Eintritt ins Berufsleben

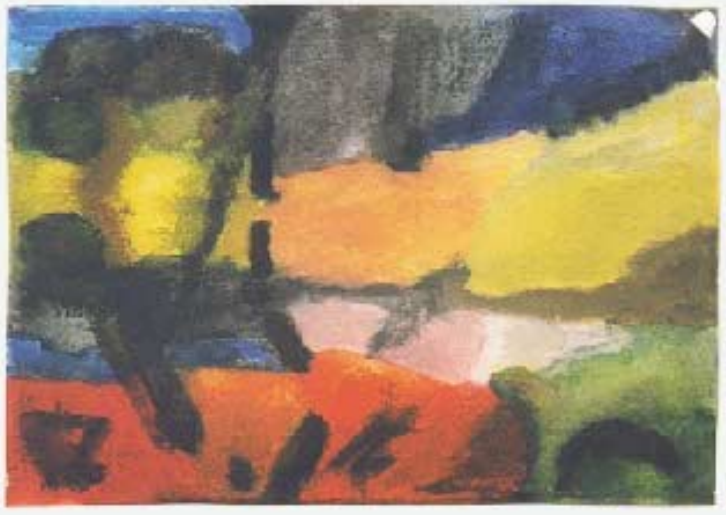

Pensionierung

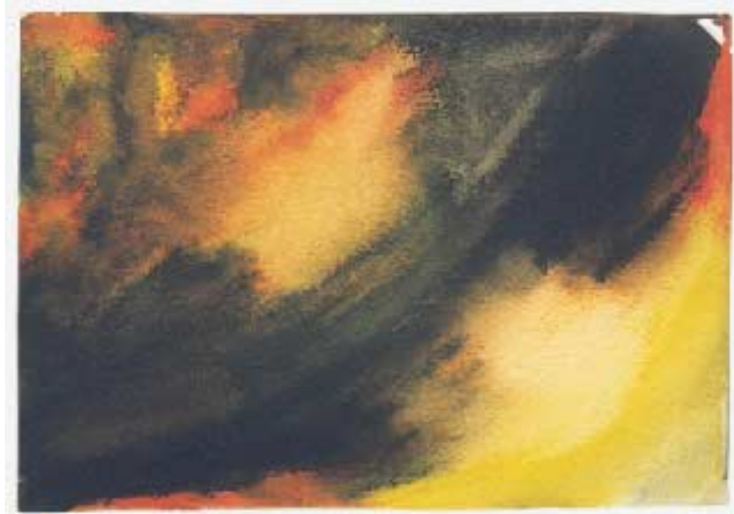

Tod 